\title{
NO SAMBA DOS PRECATÓRIOS, QUEM DANÇA SÃO OS CREDORES!
}

Coluna publicada em 9.2.2016: <https://www.conjur.com.br/2016-fev-09/ contas-vista-samba-precatorios-quem-danca-sao-credores $>$

Os precatórios, criados para regularizar o pagamento das dívidas governamentais decorrentes de sentenças judiciais condenatórias, dadas a inalienabilidade e impenhorabilidade dos bens públicos, têm sido tão maltratados nas últimas décadas de forma que hoje não conseguem mais cumprir sua função. Governantes irresponsáveis conseguiram transformá-los no melhor exemplo de ineficiência da execução e cumprimento das decisões judiciais, na mais lamentável demonstração de até onde pode ir o desrespeito às normas vigentes.

O sistema de precatórios prevê a anterior inclusão do valor ao qual o ente federado foi condenado no orçamento que está sendo elaborado, a fim de assegurar a existência dos recursos para o pagamento durante o exercício financeiro. E na ordem de apresentação, de modo a evitar que o inadimplemento do setor público resultasse em um sistema caótico de pagamento, permitindo que se pagasse a quem se quisesse e quando se quisesse, dando margem a toda sorte de privilégios e favoritismos.

Procedimentos específicos para pagamentos pela Fazenda Pública são necessários, sempre existiram em nosso ordenamento jurídico, e podem ser encontrados na Constituição de 1824, que trazia referências à regulamentação para alienação de bens públicos. Mas a Constituição de 1934 foi quem primeiramente fez referência expressa aos precatórios, na forma como hoje os conhecemos, ${ }^{1}$ passando a constar desde então em todos os textos constitucionais que se sucederam.

1 Art. 182: “Os pagamentos devidos pela Fazenda federal, em virtude de sentença judiciária, far-se-ão na ordem de apresentação dos precatórios e à conta dos créditos respectivos, sendo vedada a designação de caso ou pessoas nas verbas legais". 
A falta de seriedade com que se vem tratando a legislação, especialmente no âmbito do Direito Financeiro, tantas vezes denunciada nesta coluna, ${ }^{2}$ causou um grande estrago no sistema de precatórios. Ao longo de todas essas décadas, as normas não foram cumpridas, e muitos entes da federação não quitaram suas dívidas com precatórios.

Tais atitudes geraram dívidas de tal forma impagáveis que, em pedidos de intervenção federal, estes não foram acolhidos pela nossa Suprema Corte com fundamento na tese da "exaustão financeira", ${ }^{3}$ o que inviabilizou esta medida como forma de ver garantidos os pagamentos, e deixou os credores sem instrumentos que permitissem receber os recursos a que têm direito, muitas vezes devidos há décadas.

$\mathrm{Na}$ Constituição de 1988 o tema é regulado de forma detalhada no art. 100, e surge o primeiro "parcelamento", permitindo que os precatórios fossem pagos em oito prestações, nos termos do art. 33 do Ato das Disposiçóes Constitucionais Transitórias - ADCT. Essa Carta deu início também à criação de precatórios de natureza especial, com tratamento privilegiado, como foi o caso dos precatórios alimentares, que passaram a ter preferência na ordem de pagamento.

Com a Emenda Constitucional 30, de 2000, surgem as "requisiçôes de pequeno valor" (RPV), para as dívidas judiciais até determinado montante. A mesma emenda constitucional trouxe mais um parcelamento, permitindo o pagamento dos precatórios em dez anos (ADCT, art. 78).

Vê-se que o sistema de pagamento das dívidas judiciais por meio de precatórios passou a se tornar bastante complexo, e essas emendas fizeram da Constituição um verdadeiro "regulamento", especificando detalhes do funcionamento do sistema, acompanhado de uma multiplicidade de normas, exigindo um bom esforço para compreender as várias espécies, regimes jurídicos e ordens de pagamento existentes.

Mas nada é tão ruim que não possa piorar, como assegura uma das máximas de Lei de Murphy - que parece ser mais eficaz que qualquer Constituição!

Em 2009, na tentativa de resolver definitivamente a questão, após longa tramitação e muitos debates, surge a Emenda Constitucional 62, com o acréscimo de

2 <http://www.conjur.com.br/2015-fev-10/contas-vista-direito-financeiro-levado-serio-2015-comecou-mal; http://www.conjur.com.br/2015-dez-15/contas-vista-2015-ano-nao-terminar>; entre outras.

3 STF, IF 2915-5, j. 3.2.2003; STF, IF 1207-4, j. 19 de março de 2003; ambos rel. Presid. Min. Marco Aurélio, relator para o acórdão Min. Gilmar Mendes. 
mais um artigo ao Ato das Disposições Constitucionais Transitórias, ${ }^{4}$ o artigo 97, e nele vem mais um parcelamento, outras preferências (maiores de 60 anos ou portadores de doença grave), regime especial de pagamento baseado na receita corrente líquida, além de outras disposições.

No entanto, com as Ações Diretas de Inconstitucionalidade - ADI 4357 e 4425 -, no julgamento da medida cautelar houve o reconhecimento da inconstitucionalidade de parte de seus dispositivos, considerando nossa Suprema Corte ter havido a violação de várias cláusulas pétreas, tais como a isonomia (art. $5^{\circ}$ ), embaraço à efetividade da jurisdição $\left(\right.$ art. $\left.5^{\circ}, \mathrm{XXXV}\right)$, desrespeito à coisa julgada material (art. 50, XXXVI), ofensa à separação de poderes (art. $2^{\circ}$ ), ultraje à isonomia entre o Estado e o particular (art. $1^{\circ}$, caput, c.c. art. $5^{\circ}$, caput) e direito de propriedade (art. 50, XXII). ${ }^{5}$

Em face dessa decisão, tornou-se necessário modular seus efeitos, o que causou uma série de transtornos e insegurança jurídica no que se refere à aplicação das novas normas, em face da necessidade de definição dos índices de correção aplicáveis, das compensações, leilóes, pagamentos e respectiva ordem, acordos realizados, vinculaçôes e regimes de pagamento. Isto só veio a ocorrer recentemente, ${ }^{6}$ tendo sido estabelecida a "sobrevida" do regime especial de pagamento criado pela EC 62/2009 por mais cinco anos a contar do início de 2016, definida a aplicação do IPCA-E (Índice de Preços ao Consumidor Amplo Especial) como índice de correção dos créditos de precatórios, validadas as compensações, leilōes e pagamentos até então realizados, bem como a possibilidade de realização de acordos, dentre outros regramentos. Mas que parece não ter terminado, como se vê na discussão aberta por ocasião do julgamento dos embargos de declaração, ocorrido em 9 de dezembro de 2015 . $^{7}$

Com uma multiplicidade de espécies a serem consideradas, vários regimes aplicáveis, créditos com preferência e "superpreferência", o sistema de pagamento

4 Que de "transitórias" nada mais resta há tempos, em uma Constituição que ultrapassa os 25 anos de existência...

5 STF, ADI 4357, Plenário, rel. Min. Ayres Britto, redator do acórdão Min. Luiz Fux, acórdão de 14 de março de 2013, 326 páginas.

6 STF, Questão de ordem na ADI 4357, Plenário, rel. Min. Luiz Fux, acórdão de 25 de março de 2015, 180 páginas.

7 Veja o artigo publicado na Folha de S.Paulo e reproduzido no ConJur em 26 de janeiro de 2016, Reabrir discussão dos precatórios é um golpe na confiança do cidadão, de Marcos da Costa e Marcelo Gatti Reis Lobo. 
por precatórios não pode realmente funcionar de forma eficiente e transparente, e vai ficar longe de atingir os objetivos para os quais foi criado.

É necessário refletir ainda se é necessário manter esse complexo sistema de precatórios, com a necessidade de inclusão prévia dos valores exatos no orçamento para pagamento no ano seguinte, uma vez não haver grandes complicações em se fazer a previsão orçamentária dos valores devidos e incluir no orçamento, como ocorre com as RPV (requisições de pequeno valor). ${ }^{8}$ Tudo indica que, apesar de todas essas alterações pelas emendas constitucionais, o sistema está longe do ideal, e pode ser bem mais simples e eficiente.

Mas os problemas não param - pelo contrário, anunciam que podem piorar. Em agosto de 2015 entrou em vigor a Lei Complementar 151, que autorizou a utilização dos recursos de depósitos judiciais para pagamento de várias rubricas, entre as quais os precatórios judiciais. O que permite vislumbrar a possibilidade de, daqui a algum tempo, se a irresponsabilidade fiscal persistir, criar mais uma "dívida impagável”, desta vez representada pelos depósitos judiciais para os quais não haverá recursos que permitam quitá-los. ${ }^{9} \mathrm{O}$ pagamento dos precatórios por esta via poderá gerar um outro "precatório", com outra "fila", que, por sua vez, terá de ser regulamentada, quem sabe estabelecendo a obrigatoriedade de inclusão prévia no orçamento, e em seguida ordem de preferência no recebimento, com preferências e superpreferências...

Convém não esquecer que as dívidas do setor público têm origem bastante ampla, e os precatórios representam apenas uma parte delas. Certamente a de maior gravidade, pois representam valores que já foram reconhecidos como devidos por sentenças judiciais em caráter definitivo.

Mas hoje há muitos credores que esperam receber seus créditos e aguardam na "fila" nada regulamentada dos "restos a pagar", ${ }^{10}$ que se avolumam dia a dia, e já se constituem em verdadeiro "orçamento paralelo" de muitos entes da federação. Isso sem contar os detentores de títulos públicos e uma infinidade de formas pelas quais o setor público contrai dívidas e obrigações.

8 Nesse sentido, FAIM FILHO, Eurípedes Gomes. Requisitórios. Precatórios e requisiçôes de pequeno valor: um tema de Direito Financeiro. Tese de doutorado. São Paulo: Faculdade de Direito da USP, 2013. p. 253.

9 Assunto que foi levantado em várias colunas publicadas no ConJur: <http://www.conjur.com. br/2015-set-08/contas-vista-depositos-judiciais-litigancia-tributaria-regra-ouro-financeira>; <http://www.conjur.com.br/2015-out-06/contas-vista-depositos-judiciais-litigancia-tributaria-regra-ouro-financeira-parte>; <http://www.conjur.com.br/2015-nov-04/consultor-tributario-lc-151-leis-estaduais-depositos-juizo-violam-constituicao $>$.

10 O final de ano, as dividas e os "restos a pagar", nesta edição, p. 215-218. 
A folia de carnaval está nas ruas hoje, mas tudo indica que quem vai dançar são os credores dos precatórios, pois nestes dias de festa parece que nessa matéria estamos diante de um verdadeiro "samba do crioulo doido". Ou ainda o "samba de uma nota só”, e essa nota é o dó - dó dos credores, que ainda vão suar muito, e não vai ser nas passarelas, para receber seu dinheiro, que pelo jeito ainda vai demorar vários carnavais... 
